\title{
Water as a Natural Element for Children's Preferred Visual Landscape
}

\author{
Marina Abdullah, Izham Ghani, Mohd Zulhaili Teh, Muhammad Falihin Jasmi
}

\author{
Faculty of Architecture, Planning \& Surveying, \\ Universiti Teknologi MARA, Cawangan Perak, 32610 Seri Iskandar, Perak
}

marina84@uitm.edu.my, izham025@uitm.edu.my, mohdz841@uitm.edu.my, falihin@uitm.edu.my Tel: 019-7086307

\begin{abstract}
A child needs the best environment for the formation of themselves. Water elements may inject interest among children to be closer to their natural environment. This study focuses on the impact of water elements as an attraction to children. This study focuses on the pictorial investigation of water at outdoor spaces for six-year-old children. This study adapted the technique by Miskell (2011) in dividing places through a spectrum of naturalness helps to differentiate places from the pristine to the developed. Moreover, it guides parents towards knowing the children needs in their environment and improving happiness for their future growth.
\end{abstract}

Keywords: children; children experience; water element; visual landscape

eISSN: 2398-4287@ 2020. The Authors. Published for AMER ABRA cE-Bsby e-International Publishing House, Ltd., UK. This is an open access article under the CC BYNC-ND license (http://creativecommons.org/licenses/by-nc-nd/4.0/). Peer-review under responsibility of AMER (Association of Malaysian Environment-Behaviour Researchers), ABRA (Association of Behavioural Researchers on Asians) and cE-Bs (Centre for Environment-Behaviour Studies), Faculty of Architecture, Planning \& Surveying, UniversitiTeknologi MARA, Malaysia.

DOI: https://doi.org/10.21834/ebpj.v5i14.2177

\subsection{Introduction}

Life is wonderful when seeing children happy by doing things that they want, at the same time bringing those benefits in everyday life, their future and the environment. It is essential that they feel secured from people around them, especially those close to them such as family, teachers and friends in their daily activities. A more continuous experience is needed for the stabilisation of the characteristics of children in the process of building self-confidence and maturity in life. This study aims to seek the positive impact of water elements in the process of child formation and their response to the element, while the objectives of the study are: To understand the significance of water to children and to develop the criteria of outdoor space environments that consist of water for children and its implications to the children involved. Therefore, this study hypothesised that children are inclined to prefer and select water elements as compared to other elements such as plants, soils, and animals. They are inclined towards the water element as an entertaining game setting that can boost their happiness as well as teach them positive things to build internal skills and personal self. Thus, this study gives a first-hand view of children's comments and responds about water elements through pictorial study method. Furthermore, through this pictorial study, it is possible to examine the children's preferred water space and activities selected during childhood, especially with their families. This will assist in strengthening the engagement of children experience towards water elements, nature and its community. Together, it creates bonding with their family member physically, socially and emotionally.

However, Kates and Katz (1977) contradicted this notion as few families have limited access to the recreational water activities, which resulted in less interaction among the children with the water element in their surrounding. Those children's experience relied on urban spaces with water features. Nevertheless, the recent studies recognised social interaction between diverse communities could drop the walls of fear and segregation, which indicated children playing together from a variety of backgrounds and ages generate the infrastructure for equity in the society (UNICEF, 2012). Thus, the integration of water play in the landscape design will lead to an enhanced self and social improvement among the children.

eISSN: 2398-4287@ 2020. The Authors. Published for AMER ABRA cE-Bsby e-International Publishing House, Ltd., UK. This is an open access article under the CC BYNC-ND license (http://creativecommons.org/licenses/by-nc-nd/4.0/). Peer-review under responsibility of AMER (Association of Malaysian Environment-Behaviour Researchers), ABRA (Association of Behavioural Researchers on Asians) and cE-Bs (Centre for Environment-Behaviour Studies), Faculty of Architecture, Planning \& Surveying, UniversitiTeknologi MARA, Malaysia.

DOI: https://doi.org/10.21834/ebpj.v5i14.2177 


\subsection{Literature Review}

\subsection{The relationship between water features and children}

Children perception and needs in their play area are sometimes being neglected considering their contribution to assist designers in determining the physical environment for children's play and interactive areas. The physical environment covered by water is a topic of study. Water comprises of all categories such as ocean, lakes, springs, flush water, rivers, streams, canals, ditches and ponds. The water body area helps to stabilise the earth. It also contributes to the development and sustainability of the human life cycle, especially in the context of recreation or leisure. Children are the primary users interested in approaching the element of water.

The physical environment varies depending on the age of the child. This is the environment where they interact and respond, such as playing, talking, sleeping, singing, climbing, engaging, and others, which has an impact on the local community and the environment. Findings of previous related studies showed that children select water element as their preferred environmental element. The nature of the water environment character of their choice to enhance their enjoyment while playing is essential. Water is one of the vital life sources. In addition to being suitable for the physiological system of the body, these water elements are also beneficial in stimulating the child's developmental skills. Through playing with water, they indirectly learn to communicate the characteristics of water, cold and hot water, foam that exists in water, floating bubbles, fast-moving water, and stagnant water and others. It is beneficial in vocabulary for children. Besides, it helps children who are less conversational to give them more interaction to talk. The water environment is essential to childhood development in each way which is intellectually, emotionally, socially, spiritually and physically (Kellert, 2002). It offers experiences such as exploring, risk-taking, and fine and gross motor development and the absorption of vast amounts of basic knowledge (Johnson, 2010). It is supported by Pyle (2002) that mentioned on the disclosure to natural water environments also improves children's cognitive development by improving their consciousness, way of thinking and observational skills. Physically, Crain (2001) stated that it helps in improves their physical activities, expand their powers or skills of observation and creativity and instils a sense of peace, sense of place and ownership, and being at one with the world.

Children can experience movement in shallow, semi-deep and deep water, as well as splash water, tap water, pour water and more. This activity can enhance a variety of children's experiences and emotions. Besides, they can distinguish between waterways in how they feel safe and unsafe. Lots of emotions that bring ones thought, feelings, and personal behaviour will happen when spending time with water, either individually or in a group. Those emotions influenced their everyday landscape. Moreover, it acts as a recreation place for people, especially children.

Water is a game mechanism that can help to strengthen the bond between children, even though they may be physically different. Playing with water or underwater can enhance social interaction among children, especially in terms of conversation and cause and effect behaviours. Hence, it also becomes one of the essential elements that influenced human being and sustainable city's development towards a better living environment. Water is one of the prominent natural elements that need to be studied further to see the relationship of nature with children's interaction not only at outdoor spaces but also in indoor spaces. Instead, many landscape architects integrated water as part of the design to provide both aesthetical and functional value while entertaining and relaxing people (Nasar \& Lin, 2003).

\subsection{The importance of water play character}

Existence of research by different fields around the globe has established the significance of children's water play for both children's individual development and the society benefits as a whole. Both indoor and outdoor water play spaces were considered significant. Water play activities for children living in urban and rural areas vary. It encompasses the speed of movement and alertness of children in choosing a water play location to play. This provides the opportunity for children to identify the cause and effect of gravity, self-float, strength of difference when they are on land and in the water. In addition, they could learn some mathematical concepts about water weight comparison, water ratio, water quality in life and others. Their physical interaction with water will help them remember their life experiences through physical and mental senses.

Five developmental themes have been recognized as (i) environmental, (ii) physiological, (iii) creative, (iv) educational and (v) social (Han \& Cui, 2013). Additionally, there are five development aspects of children play; (i) physical faculties, (ii) creativity, (iii) sociality, (iv) sensitivity and (v) readiness to challenge as recommended by Senda (2012). Czalczynska-Podolska (2014) proposed that water play environment (indoor and outdoor) should be constructed to provision physical, social, emotional, and cognitive development in order to function efficiently. Affording a sense of control and authorisation or agency and security is also important to ensure a good experience of outdoor water play space for young children (White \& Woolley, 2014). Site leaders must also consider water safety and potential water hazards when undertaking a risk assessment (Government of South Australia, 2019). Hence, despite the all character of outdoors and indoor water play for children, the security of the particular space needs to be highlighted, as it will reduce parents' anxiety and allow their children to explore and experience the water play with adequate supervision.

\subsection{Methodology}

The primary data collection method in this study is through a pictorial study. Photos have been arranged, selected and filtered for the study. The study covered six-year-old respondents and their preschool teacher at Seri Iskandar in Perak. Preschools such Tadika Pintas, Tadika Mutiara Montessori and Pusat Asuhan Tunas Islam (PASTI) in Taman Maju, Seri Iskandar have been selected for the study as the schools cater for children range aged from four to six years old. The respondents selected consisted of 20 children from all three schools (Table 1). Six-year-olds children are chosen because at this stage, and they are capable to make better choices than children aged four and five. They can communicate well orally and are able to identify elements and objects in the environment. This selection 
process has been conducted and refined by preschools teachers of each school covering aspects such as children's ability to identify objects, memorise and write alphabets, write their own name on paper and organise objects. This is because the study involves taking children response in identifying elements such as plants, water, animals and colours, writing and organising photos. This study will bring an introduction to the children on water elements and how to respond and appreciate their whole surrounding environment, especially those towards water recreation places.

The photos of water places in an outdoor environment are based on the attraction places in Taiping, Perak. During the first phase, several photos were selected and informed to the teachers; however, most of the teachers in the kindergarten suggested that the photos are preferably selected of not more than three. This is due to the children's own constraints who tend to be distracted because of the abundance of photos and which creates less focus when making the selection. The selected photos are analysed according to the spectrum of naturalness by Boffa Miskell and Lucas Associates, (2011) and from expert comments. This method gives clear identification in planning public realm for assessing the natural and built-up area, together provide a clear justification in natural segregation places for the social environment.

Table 1. Respondents of the study according to gender age 6 years old

\begin{tabular}{ccc}
\hline Gender & Frequency & Percentage \\
\hline Boys & 10 & 50.0 \\
Girls & 10 & 50.0 \\
TOTAL & 20 & 100.0 \\
\hline \multicolumn{3}{c}{ (Source: Authors) }
\end{tabular}

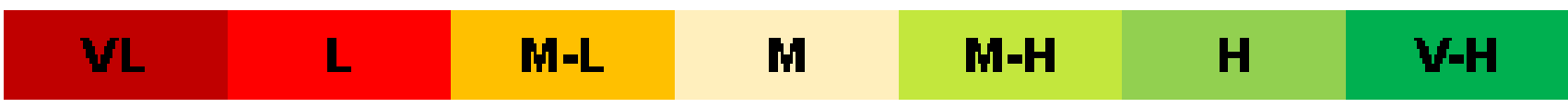

Fig. 1: Scale-like spectrum of naturalness (Source: Miskell, 2017)

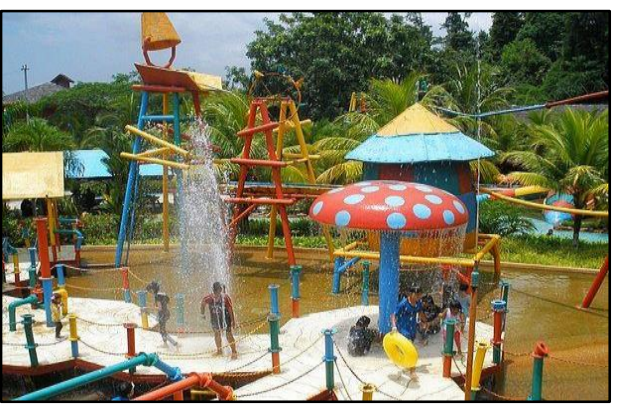

(a: L/1)

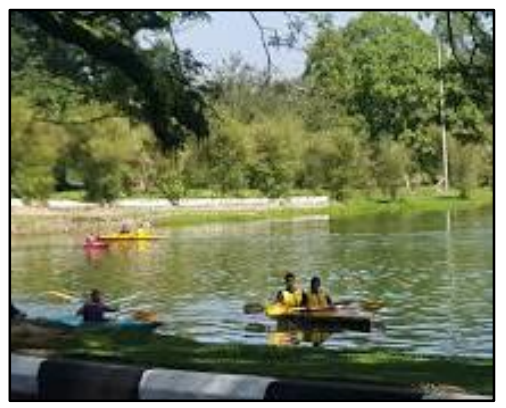

(b: $\mathrm{MH} / 2$ )

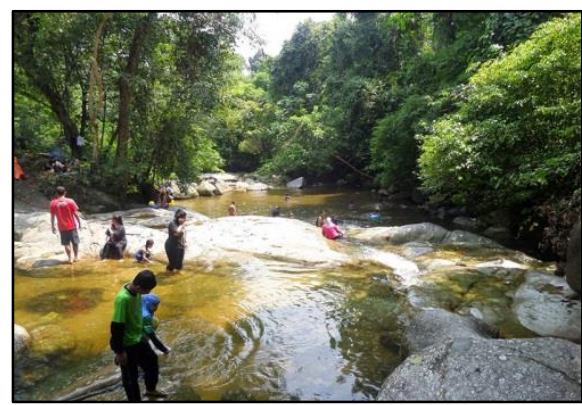

(c: $\mathrm{H} / 3$ )

Fig. 2:(a) Bukit Merah Waterpark; (b) Taman Tasik Taiping; (c) Burmese Pool, Bukit Larut (Source: Authors)

The Bukit Merah Waterpark, Taman Tasik Taiping and Burmese Pool at Larut were popularly selected, and this is due to several factors. The Bukit Merah Waterpark is one of the most visited man-made waterparks that have many facilities, and lots of water activities offered. It also symbolises active water play places that children can touch and feel the water during playing. Secondly, the Taman Tasik Taiping were selected where lakes area very dominant, but the water is just for viewing and canoeing and not freely accessible to touch. Thirdly, the Burmese Pool at Larut was selected, as a water place with a more natural setting. This natural water pool consists of boulders, flora and fauna offering more water interactions and activities.

All the three images were briefly explained to the children on its contents. After that, children start to identify and express feelings and comments about those photos. At this stage, lots of skills on recognising, identifying and communicating each other are being developed. Lastly, photos must be arranged vertically and glued by them. They arranged from most preferred which will be placed at the top, and less preferred at the bottom. All those photos arranged are analysed and recorded. Then, the photos will be sorted into the scale of naturalness from modified to pristine. With reference to Miskell (2011), seven scales of spectrum ranging from spectrum colour of red very low $(V L)$ where it was modified, low $(L)$, medium-low $(M-L)$, medium $(M)$, medium-high $(M-H)$, high $(H)$ and very high $(V-H)$ which is indigenous or pristine. This scaling attempts to include the best possible rating that suits different types of naturalness of the environments. All three of these images should be chosen by these children to get the environment of the water activity where they preferred most. The results of the data of images analysis process are conducted according to the most preferred place of water environment preferred by children. This analysis process is generated using IBM SPSS Statistics 24 software.

Limitation of the study exists when children from a variety of family background and family history influence the choices about the water element environment that made them enjoyable to play. It may be due to the factors of their daily activities when with the family and the local environment. 


\subsection{Findings}

From the study, it is essential to know the appropriateness of children's outdoor water play environment and where it should be created for improving the development of self-experience of a child and its injections in tourist attractions in Malaysia for children to visit with their family. The analysis of the study conducted on 20 six-year-old children found that children choose the highest labelled L/1 photo, which is $85 \%$ selected by 17 out of 20 children. Most of them react actively by jumping and showing lots of excitements when viewing this photo. Furthermore, if the child meets their enjoyment and fun, their emotional and ability will be increased. Five numbers of children informed that they wanted to go there with families and friends. The second-highest selected photo is labelled $\mathrm{H} / 3$, which makes up to $75 \%$ or a total of 15 children have chosen the photo for their second preferred place. This wilderness photo obtains comments from two children that they scared falling into the rocks as the place is slippery but love to observe the creatures and habitat exist inside it. Half of the total of children mentioned that the area is full of snakes, spiders and crocodiles. They are curious to see those wild animals and where it lives. The observation shows that despite fear, they are eager to see the spaces even though with a lack of engagement and information with it. Children are less likely to be exposed to this place without having the opportunity to know the beauty of this wilderness place. They seem to like the natural water play but less knowledge on how to manage themselves and the security aspect. Lastly, a photo labelled $\mathrm{MH} / 2$ are selected by 17 children, which makes up to $85 \%$ of choosing it as the final preferred water place for having activities. They are less likely to choose water spaces that lack structures to play and less interaction to enjoying the water. The overall results are summarised in Table 2.

Table 2.Percentage of preferred places photo selection

\begin{tabular}{cccc}
\hline $\begin{array}{c}\text { Preferred } \\
\text { Selection }\end{array}$ & Low (L/1) & $\begin{array}{c}\text { Medium-High } \\
(\mathrm{MH} / 2)\end{array}$ & $\begin{array}{c}\text { High } \\
(\mathrm{H} / 3)\end{array}$ \\
\hline & & 5 & 10 \\
1 & $\mathbf{8 5}$ & 10 & $\mathbf{7 5}$ \\
2 & 15 & $\mathbf{8 5}$ & 15 \\
\hline Total & 0 & 100.0 & 100.0 \\
\hline
\end{tabular}

(Source: Authors)

\subsection{Discussion}

The results indicated that the majority of the children age six years old in Seri Iskandar, Perak mostly preferred water spaces characters that provide opportunities to touch and experience with plenty of games and activities. This study explores the children's preferable activities at water spaces that trigger the feeling of happiness and finding more about activities that can be conducted during childhood stages.

According to the interviews with the children, the study found that children preferred outdoor activities as compared to indoor due to the freedom of observing the surroundings without any limitations. The diverse coloured structures provided at the water activities area attracts the children's interest. This form of attraction was proved by Bozkurt et al. (2020) that children are more attracted to play with constructed elements compared to natural water features. Constructed water features which are not explicitly designed for children's play can provide perceived affordances which children can actualise. Children love to express their ability and performing various actions such as sliding, jumping, walking through the water, make friends when playing, splashing water, and many more. They can practice swimming, snorkelling, splashing water, balancing their body to float and other activities. Those exercises are essential to sustain a healthy lifestyle. Outdoor water spaces consist of water served as a place for children activities gives a positive impact. Water plays develop fine and gross motor skills of hand-eye coordination through actions like pouring, squirting, scrubbing, stirring and squeezing. Besides, they also learn to speak new words such as wet, damp, splash, floating and others. It can help in communication and interaction with each other besides playing with water.

Based on children point of view, they highlighted that natural water places-like such MH/2 photo at Taman Tasik Taiping possess minimal activities and less access to the water elements. They commented that the water in the photo was too tricky and dangerous to touch and interact. Their preference is to touch the water without any hindrance and consider it safer and less dangerous. This may also be driven by several other factors, such as the current family background and approach.

\subsection{Conclusion \& Recommendations}

In conclusion, this study showed that children at selected preschools around Seri Iskandar, Perak love to explore water and prefer colourful water features, rather than natural water features to carry out activities that excite them. Most children prefer to create plenty of outdoor activities that are freely accessible without restrictions. Their top choice is the built-in water play structure that contains slides, swing, tunnel, circular play structures and others, as opposed to natural elements such as rock and water. The location of the play spaces, whether in urban or remote areas, are not directly considered in the selection by the children. However, it is the attraction of the equipment provided are selected which allow exploration of the water features by using all of the senses, specifically touch senses, hearing, and physical movements with water.

Furthermore, at this stage, children are inclined to show their physical, mental, emotional and social strength. They will express their joy 
if they can touch the water, tap the water, sink in the water, cross the water, and other water interactions. It is also a way of dealing with children's sadness. They love what they want to do so with their family and friends instead of experiencing it alone. In addition, schools should structure their learning activities by using natural elements such as water, rocks, sand so that they can be closer to nature. Children today are incredibly active and creative in exploring all aspects of learning within their environment. However, the supervision of the authorities and the safety aspects of many parties are essential in order to reduce the risk of harm when performing water activities. Children need caregivers to observe and conduct them as they engage in activities. Water can be a calming and soothing thing, but water also can be hazardous. In Malaysia, specifically in the study area in Seri Iskandar, Perak, its hot and humid climates can reach up to 36 degrees Celsius which demands the installation of cooling elements such as water. In this area, especially when it is raining, it is not uncommon to see children playing with water around their house. It is a pleasant sight considering they still prefer to play with their natural surroundings as most of today's increasingly active children are engaged in passive activities with digital gaming and mobile devices. Therefore, the selection of activities during free time, supervision by responsible persons, the security of the available spaces and the duration for activities are essential to ensure the quality of the child's physical, mental, emotional and social development as a whole. Future recommendation of this study is to explore further other locations of water parks around Malaysia that have wellconstructed and safety-equipped play structures that are frequently visited by children and families. This will also benefit in providing better knowledge for children and parents in Malaysia and abroad to find an ideal place for children to be more productive and have a high level of sensitivity towards their whole environment.

\section{References}

Boffa Miskell \& Lucas Associates (2011). Canterbury Regional Landscape Study, Volume 2. Prepared for Canterbury Regional Council.

Bozkurt, M., \& Woolley, H. (2020). Let's splash: Children's active and passive water play in constructed and natural water features in urban green spaces in Sheffield. Urban Forestry and Urban Greening, 52. https://doi.org/10.1016/j.ufug.2020.126696

Crain, W. (2001). Now Nature Helps Children Develop. Montessori Life, Summer 2001.

Czalczynska-Podolska, M. (2014). The impact of playground spatial features on children's play and activity forms: An evaluation of contemporary playgrounds' play and social value. Journal of Environmental Psychology, 38, page 132-142

Government of South Australia (2019). Preschool Water Safety Procedure, Department for Education, page 2-3

Han, X.L. \& Cui, R.D. (2013). Decision-making Mechanism of the Construction of Children's Outdoor Playground in Chinese Urban Community. Community Design, (5), page $35-39$

Johnson, J., Christie, J., \& Wardle, F. (2010). The Importance of Outdoor Play for Children. Retrieved from: http://www.communityplaythings.com/resources/articles/2010/outdoor- play.

Kates, R. W., \& Katz, C. R. (1977). The Hydrologic Cycle and The Wisdom of The Child. Geographical Review, 67(1), page 51-62

Kellert, S.R. (2002). Experiencing nature: Affective, cognitive, and evaluative development, in children and nature: Psychological, sociocultural, and evolutionary investigations. Cambridge, MA: The MIT Press.

Nasar, J., \& Lin, Y. H. (2003). Evaluative Responses to Five Kinds of Water Features. Landscape Research, 28(4), page 441-450

Pyle, R. (2002). Eden in a Vacant Lot: Special Places, Species and Kids in Community of Life. In: Children and Nature: Psychological, Socio-cultural and Evolutionary Investigations. Kahn, P.H. and Kellert, S.R. (eds) Cambridge: MIT Press.

Senda, M. (2012). What is a good environment for children's growth. Landscape Architecture, 03, 149-151.

Stephen R. K. (2005). Reflections on Children's Experience of Nature. C\&NN Leadership Writing Series. Volume one: Number 2

UNICEF (2012). State of the World's Children 2012: Children in a Urban World. New York: UNICEF

White, J., \& Woolley, H. (2014). What makes a good outdoor environment for young children? In T. Maynard, \& J. Waters (Eds.), Exploring outdoor play in early years (pp.29-41). New York: Open University Press. 